Accepted for publication in 'Journal of Behavior Therapy and Experimental Psychiatry'

Note: This is an uncorrected version of an author's manuscript accepted for publication.

Copyediting, typesetting, and review of the resulting proofs will be undertaken on this manuscript before final publication. During production and pre-press, errors may be discovered that could affect the content.

\title{
INTERNAL SHIFTING IMPAIRMENTS IN RESPONSE TO EMOTIONAL INFORMATION IN DYSPHORIC ADOLESCENTS
}

\author{
Laura Wante $^{1}$, Sven C. Mueller ${ }^{2}$, Ineke Demeyer ${ }^{2}$, Tiffany Naets ${ }^{1}$, Caroline Braet ${ }^{1}$ \\ Ghent University
}

Author Note

${ }^{1}$ Department of Developmental, Personality, and Social Psychology, Ghent University, Ghent, Belgium

${ }^{2}$ Department of Experimental Clinical and Health Psychology, Ghent University, Ghent, Belgium 


\begin{abstract}
Background and Objectives: Previous studies have suggested that internal cognitive control impairments may play an important role in the development of depression. Despite a growing body of research in adults, the ability to shift internal attention between mental representations in working memory has received little attention in younger populations. This study investigated internal shifting capacity between emotional and non-emotional information in dysphoric and non-dysphoric adolescents.
\end{abstract}

Methods: Twenty dysphoric and 34 non-dysphoric adolescents (10-17 years) completed an Internal Shifting Task, with pictures of angry and neutral faces, to measure the ability to shift attention between information held in working memory.

Results: Dysphoric adolescents showed specific shifting impairments when processing emotional material relative to non-dysphoric adolescents. Valence-specific analyses revealed that shifting was particularly impaired when shifting from negative to neutral information. By comparison, relative to non-dysphoric adolescents, dysphoric adolescents did not show shifting impairments when non-emotional features of the pictures had to be processed.

Limitations: The study is limited by the absence of a structured clinical interview as dysphoria was determined dimensionally. Furthermore, a comparison of the effects of different negative stimuli on shifting could not be made since sad stimuli were not included in the stimulus set.

Conclusions: The results confirm the link between depressive symptoms and emotion-specific shifting impairments in adolescents and indicate that targeting shifting ability in response to emotional stimuli may be a promising avenue for prevention programs. Longitudinal research is needed to replicate results and to explore the role of internal shifting impairments in the etiology and maintenance of depression.

Keywords: Dysphoria; Shifting; Working memory; Emotion; Adolescents 


\section{Introduction}

Depressive symptoms in adolescents are common (Balazs, 2013) and have a variety of negative consequences, such as impaired social relationships and an increased risk for suicide (Birmaher et al., 1996; Horowitz \& Garber, 2006). Moreover, adolescent depressive symptoms are highly predictive for chronic and severe depressive episodes in adulthood (Lewinsohn, Rohde, Seeley, Klein, \& Gotlib, 2000), which indicates the need to study underlying cognitive processes in dysphoric adolescents before a chronic course emerges.

Cognitive theories have mainly focused on the content of depressive cognition and assigned a crucial role to negative schemas of the self, world, and future in the development and persistence of depression (Beck, 1976). The proposition that cognitive schemas have a major influence on the processing of information stimulated research on the relationship between cognitive processes and depressive symptoms. Results of these studies provided evidence for depression-related information processing biases (Neshat-Doost, Taghavi, Moradi, Yule, \& Dalgleish, 1998; Timbremont, Braet, Bosmans, \& Van Vlierberghe, 2008) and indicated a better memory for negative information and an attentional bias towards negative information among adolescents who are currently depressed or at risk for depression (Gibb, Benas, Grassia, \& McGeary, 2009; Hankin, Gibb, Abela, \& Flory, 2010). It is assumed that these negative processing biases lead to repetitive negative thoughts (i.e. rumination) and sustained negative affect, which in turn contribute to and intensify depressive symptoms (Clark \& Beck, 2010). Despite the interesting findings regarding depressogenic information processing, so far it is still unclear to what extent adolescent depressive symptoms are associated with impairments on the level of fundamental cognitive control processes, which refer to executive functions such as working memory. Yet, the investigation of such processes is of particular interest since it has been shown that the capacity to cognitively control incoming 
information positively impacts one's ability to deal with stressful events and to manage emotional responses (Ochsner \& Gross, 2005).

\subsection{Depressive Symptoms and Cognitive Control Impairments}

Cognitive control refers to the ability to selectively attend to relevant stimuli, select and maintain relevant goals, and inhibit the processing or response to irrelevant or previously relevant stimuli (Brydges, Anderson, Reid, \& Fox, 2013; Ridderinkhof, Ullsperger, Crone, \& Nieuwenhuiss, 2004). This ability is related to three important executive functions: shifting between tasks or mental sets (shifting), inhibiting dominant responses or irrelevant information (inhibition), and monitoring and updating the contents of working memory (updating) (Miyake et al., 2000). Recently, it has been proposed that impaired cognitive control may be an important component for understanding prolonged negative affect and recurrent negative thoughts in depression (Joormann \& D'Avanzato, 2010; Koster, De Lissnyder, Derakshan, \& De Raedt, 2011). The majority of the past studies on cognitive control in depressed or dysphoric adolescents have used cognitive control tasks including non-emotional information and provided mixed results with only a few studies indicating a clear group difference (for a review see Vilgis, Silk, \& Vance, 2015). The little research that demonstrated group differences regarding cognitive control ability showed that depressed adolescents were less accurate (i.e., higher error rates) and responded more slowly (i.e., higher response times) compared to healthy adolescents (Bloch et al., 2013; Gunther, Konrad, De Brito, Herpertz-Dahlmann, \& Vloet, 2011; Hardin, Schroth, Pine, \& Ernst, 2007). However, multiple studies on cognitive control functions yielded mixed or no results (Han et al., 2012; Kyte, Goodyer, \& Sahakian, 2005; Wilkinson \& Goodyer, 2006). For instance, previous studies investigating general shifting, determined by tests such as the Wisconsin Card Sorting Test (WCST; Grant \& Berg, 1948), were inconclusive showing either no difference between depressed adolescents and healthy controls (Favre et al., 2009) or a lower score on shifting in the depressed group (Gunther et al., 
2011; Holler, Kavanaugh, \& Cook, 2014). By contrast, studies examining inhibition, with an antisaccadic eye movement task (Hardin et al., 2007) or a go/no-go task (Gunther et al., 2011) provided some support for impaired inhibition in depressed or dysphoric adolescents, yet, empirical evidence is far from being consistent (Vilgis et al., 2015).

Given prior inconclusive results regarding general cognitive control impairments, one possibility is that cognitive control in dysphoric or depressed adolescents might be particularly disturbed when processing emotional information (Joormann, Yoon, \& Zetsche, 2007; Koster et al., 2011; Vilgis et al., 2015). Although research using cognitive control tasks including emotional stimuli in pediatric mood disorders and dysphoric adolescents is rather scarce (for a review see Mueller, 2011), a few studies have provided such evidence. Ladouceur et al. (2005) and Tavitian et al. (2014) administered an Emotion $N$-back task and found evidence for working memory impairments in the presence of emotional and neutral information in depressed youngsters compared to healthy controls. Furthermore, results from the Affective go/no go task also support impaired processing of negative stimuli in adolescents suffering from depression (Kyte et al., 2005; Ladouceur et al., 2006; Maalouf et al., 2012). Finally, a study using the Negative Affective Priming task showed a higher interference and inhibition of negative stimuli in dysphoric adolescents compared to healthy controls (Wante, Mueller, Demeyer, De Raedt, \& Braet, 2015). Although the aforementioned studies provide initial evidence for dysfunctional cognitive control over emotional stimuli, it has recently been proposed that depressed people might experience specific difficulties with internal cognitive control rather than with external cognitive control processes (Koster, De Lissnyder, \& De Raedt, 2013).

\subsection{Depressive Symptoms and Internal Shifting Ability}

Whereas external cognitive control refers to the selection and modulation of external information, such as perceptual attributes of cues or targets, internal cognitive control can be described as the ability to process and modulate internally generated information, such as 
mental sets in working memory (Chun, Golomb, \& Turk-Browne, 2011; Wager, Jonides, \& Smith, 2006). Impaired internal control over negative thoughts may result in difficulties regulating negative affect and thus might be of particular relevance in the development of depressive symptoms (Koster et al., 2013). An interesting paradigm to explore shifting between mental representations in working memory is the Internal Shifting Task (IST; Chambers, Lo, \& Allen, 2008; De Lissnyder, Koster, \& De Raedt, 2012), which is an affective variant of the shifting task of Garavan (1998) and Gehring, Bryck, Jonides, Albin, and Badre (2003). The IST used in this study includes pictures of faces and consists of an emotional and a non-emotional condition. In the emotional condition, participants are asked to perform a silent mental count of the number of negative and neutral faces. In the non-emotional condition, participants are instructed to mentally count the amount of male and female faces. The IST design allows to measure efficiency of general shifting (across emotional and non-emotional condition), condition-specific shifting (emotional condition vs. non-emotional condition), and valencespecific shifting (shifting from negative to neutral or vice versa). Results of a study in depressed adolescents and young adults using an IST with neutral and affective words revealed greater shifting difficulties in the emotional condition compared to healthy controls (Lo \& Allen, 2011). Moreover results of prospective studies in adults using a pictorial IST indicated that emotionspecific shifting impairments are associated with increased rumination in response to stress (De Lissnyder, Koster, Goubert, et al., 2012) and play an important role in the prediction of depressive symptoms at one year follow up (Demeyer, De Lissnyder, Koster, \& De Raedt, 2012).

\subsection{The Current Study}

Despite the increased risk for an adult depressive episode in adolescents with depressive symptoms (Pine, Cohen, Cohen, \& Brook, 1999), research on the role of internal cognitive control in response to emotional stimuli in dysphoric adolescents remains scarce. The present 
study aimed to examine internal shifting ability in dysphoric adolescents with the use of the IST including pictures of angry and neutral faces (De Lissnyder, Koster, \& De Raedt, 2012). In line with prior shifting studies in adults (De Lissnyder, Koster, Derakshan, \& De Raedt, 2010; De Lissnyder, Koster, Everaert, et al., 2012; De Lissnyder, Koster, Goubert, et al., 2012; Demeyer et al., 2012; Koster et al., 2013), we included angry faces as negative target stimuli in that these kind of emotional stimuli are thought of bearing direct personal relevance to adolescents suffering from depressive symptoms and can be associated with depression-related interpersonal difficulties and schemas of social rejection (Gotlib, Krasnoperova, Yue, \& Joormann, 2004; Hames, Hagan, \& Joine, 2013; Mueller, De Rubeis, Lange, Pawelzik, \& Sutterlin, 2016). According to interpersonal theories of depression, depressed individuals engage in inappropriate social behaviors that are likely to elicit social rejection, which in turn confirms negative schemas and increases depressive symptoms (Coyne, 1976; Joiner, Alfano, \& Metalsky, 1992). Since angry faces might activate depression-related schemas of social rejection and therewith increase negative affect, these stimuli may strongly attract attention in dysphoric adolescents (Gilboa-Schechtman, Ben-Artzi, Jeczemien, Marom, \& Hermesh, 2004).

The study had three specific goals. First, we investigated whether dysphoric adolescents relative to unaffected adolescents showed general shifting impairments. Based on prior research in depressed or dysphoric adolescents which failed to find general cognitive control deficits (Vilgis et al., 2015), and shifting deficits in particular (Favre et al., 2009), we expected no differences between the groups with regard to general shifting impairments. Second, we aimed to investigate to what extent dysphoric adolescents showed specific shifting impairments when processing the emotional features of the target stimuli. Drawing on a few studies investigating cognitive control of emotional stimuli in adolescents with elevated depressive symptoms (Maalouf et al., 2012; Tavitian et al., 2014; Wante et al., 2015) and prior internal shifting studies among currently depressed and at-risk individuals (De Lissnyder, Koster, Goubert, et al., 2012; 
Demeyer et al., 2012; Koster et al., 2013; Lo \& Allen, 2011), we hypothesized a greater shift cost in the emotional condition compared to the non-emotional condition only in the dysphoric group. Finally, we explored whether dysphoric adolescents showed valence-specific shifting impairments. On the basis of recent cognitive models of depression (Joormann \& D'Avanzato, 2010; Koster et al., 2011), we predicted higher shift costs related to shifting from angry to neutral information compared to shifting from neutral to angry information in dysphoric adolescents but not in non-dysphoric adolescents.

Because of the continuous development of cognitive control processes, such as shifting between mental sets, during adolescence (Diamond, 2002) and gender differences in the neural processes of cognitive control (Koch et al., 2007; Li et al., 2009), age and gender were included as standard covariates throughout all analyses. Moreover, to filter out the confounding effects of other relevant variables that may impact differences shifting ability between the dysphoric and the non-dysphoric group, we explored the impact of several covariates of no interest in a second round of analyses. Based on previous adult studies indicating an association between rumination and shifting (De Lissnyder et al., 2010; De Lissnyder, Koster, Goubert, et al., 2012; Demeyer et al., 2012; Koster et al., 2013), we added rumination as a control variable to exclude its potential contribution to the results. Furthermore, since dysphoria and anxiety are frequently associated with one another (AACAP, 2007) and to rule out a potential contributing factor, we added anxiety symptoms as a control variable. Next, we controlled for other co-occurring symptoms besides anxiety that could influence shifting ability in the dysphoric group by including the overall level of psychopathology symptoms. Finally, given that working memory and intelligence appear to be highly correlated (Benedek, Jauk, Sommer, Arendasy, \& Neubauer, 2014), we also controlled for intelligence.

\section{Materials and Methods}

\subsection{Participants}


Eighty-two adolescents between 10 and 17 years of age $\left(54 \%\right.$ female, $M_{\mathrm{age}}=12.30, S D=$ 1.65) volunteered for this study. In order to obtain a youth sample with a broad range of depressive symptoms, non-referred $(N=41$ or $50 \%)$, at-risk $(N=24$ or $29 \%)$, and referred adolescents $(N=17$ or $21 \%$ ) were included in the sample. Non-referred adolescents were recruited through advertising in schools. At-risk youngsters were selected from a screening sample of youngsters who were participating in a larger, school-based study. Youngsters from the screening sample were invited to the study if their scores were above or equal to a cut-off score of 11 on the Children's Depression Inventory (CDI; Kovacs, 1992; Mattison, Handford, Kales, \& Goodman, 1990). A cut-off score of 11 on the CDI has been shown to have relatively good psychometric properties in predicting depression in youth and is considered to represent mild levels of depression (Kaslow, Rehm, \& Siegel, 1984; Shemesh et al., 2005; Worchel et al., 1990). The referred adolescents were recruited from two clinical centers and were invited if they were referred for treatment of internalizing problems. Twenty-eight participants were excluded from the analyses due to accuracy rates below $60 \%$ on the IST. These participants did not significantly differ from the final sample on the basis of gender, age, intelligence, or depressive symptoms (all $p s>$.085). This resulted in a final sample of 54 adolescents (57\% female, $M_{\text {age }}=12.30, S D=1.19$; see Table 1). Based on their CDI scores at the moment of testing, participants were classified as dysphoric $(\mathrm{CDI} \geq 11 ; n=20)$ or non-dysphoric $(\mathrm{CDI}<$ $11 ; n=34)$. In the dysphoric group (range CDI scores $=11-25), 25 \%$ were from the referred sample, $45 \%$ from the at-risk sample, and $30 \%$ from the non-referred sample, whereas in the non-dysphoric group (range CDI scores $=0-10$ ), 67\% were from the non-referred sample, $15 \%$ from the at-risk sample, and $18 \%$ from the referred sample. Age and gender of the participants were included as standard covariates in all analyses. The research protocol was approved by the Ethics Committee of Ghent University Hospital. Youngsters signed informed assent while legal 
guardians signed informed consent. After completing the questionnaires and the task, participants were compensated with two cinema tickets.

Table 1

Characteristics of the Study Sample

\begin{tabular}{lll}
\hline & Dysphoric & Non-dysphoric \\
\hline$N$ & 20 & 34 \\
Depression*** & $15.80(4.50)$ & $6.82(2.81)$ \\
Rumination & $18.92(4.71)$ & $16.78(4.83)$ \\
Anxiety*** & $40.85(5.45)$ & $33.60(6.64)$ \\
Total problem score* & $41.00(26.20)$ & $26.52(20.41)$ \\
Age** & $13.10(1.92)$ & $11.82(1.55)$ \\
Intelligence & $43.15(6.78)$ & $41.64(6.33)$ \\
Sex (female/male) & $14 / 6$ & $17 / 17$ \\
\hline
\end{tabular}

Note. Standard deviations are shown in parentheses. ${ }^{*} p<.05 ; * * p \leq .01 ; * * * p<.001$

\subsection{Measures}

\subsubsection{Depressive symptoms.}

The CDI (Kovacs, 1992; Dutch version by Timbremont \& Braet, 2002) is a 27-item selfreport questionnaire designed to assess depressive symptoms in youth. Each item has three response options, which vary in severity (e.g., "I do most things wrong", "I do many things wrong", "I do everything wrong"). The CDI showed good psychometric qualities in terms of internal consistency and test-retest reliability in non-clinical samples (Craighead, Smucker, Craighead, \& Ilardi, 1998; Timbremont \& Braet, 2002). Cronbach's alpha on the CDI in this sample was $\alpha=.80$. 


\subsubsection{Rumination.}

The FEEL-KJ is a 90 -item self-report measure and is designed to assess adaptive and maladaptive emotion regulation (ER) strategies in response to anxiety, sadness, and anger (Cracco, Van Durme, \& Braet, 2015). The items are rated on a five-point scale, ranging from never to almost always. The FEEL-KJ has been shown to have good psychometric qualities, in terms of reliability and validity (Cracco et al., 2015; Grob \& Smolenski, 2005). In the current study, only the subscale "Rumination" was used and Cronbach's alpha was .69.

\subsubsection{Trait Anxiety.}

The trait version of the State-Trait Anxiety Inventory for Children (STAI-TC; Bakker, Wieringen, Ploeg, \& Spielberger, 2004; Spielberger, 1973) is a 20-item self-report questionnaire that assesses the frequency and intensity of anxiety symptoms. Items are rated on a 3-point Likert scale with $1=$ 'almost never' and ' 3 ' = often. The STAI-TC is considered as a reliable and valid measure for assessing anxiety symptoms in youngsters. Internal consistency in this study was good with a Cronbach's alpha of .86

\subsubsection{General Psychopathology}

The Child Behavior Checklist is a parent-report questionnaire measuring emotional and behavioral problems in youngsters (CBCL; Achenbach \& Rescorla, 2001; Dutch version by Verhulst, Ende, \& Koot, 1996). It consists of 113 items, which are scored on a three-point scale. In this study, only the CBCL Total Problem scale was used and Cronbach's alpha was good with $\alpha=.95$.

\subsubsection{Intelligence}

Raven's Standard Progressive Matrices (SPM) is a non-verbal IQ measure that consists of 60 incomplete matrices (Raven, Court, \& Raven, 1977). For each matrix, the participant is presented with 6 pieces and is instructed to choose the one that best fits the missing part. Results of psychometric studies indicate that SPM is a good predictor of fluid intelligence and correlates 
strongly with general intelligence (Spearman's g; e.g., Carroll, 1993; Flanagan \& McGrew, 1998; Rushton, 1998).

\subsubsection{Internal Shifting Task}

The IST (De Lissnyder, Koster, \& De Raedt, 2012) was programmed using the E-prime 2.0 software package and was run on a laptop with a $72-\mathrm{Hz}, 17-$ inch color monitor. The pictorial stimuli were selected from two validated databases: a recently developed database of child face images (Verfaillie, Theuwis, \& Wante, 2012) and the child faces of the Radboud Faces Database (Langner et al., 2010). The pictures were set at 360 x 360 pixels and were adjusted to reduce interference of background stimuli (hair). The final stimulus set included 24 neutral faces and 24 angry faces. Participants were told that pictures of faces would appear in the center of the screen one at a time. They were asked to silently count the amount of pictures in a certain category observed over the block of trials. There were two task conditions: an emotional condition and a non-emotional condition. In the emotional condition (or emotion condition), participants had to focus on the emotion of the pictures and were asked to perform a silent mental count of the number of angry and neutral faces. In the non-emotional condition (or gender condition) participants had to focus on the gender of the pictures and were asked to mentally count of the number of male and female faces. When a stimulus was presented, the subjects had to press the spacebar as quickly as possible to indicate that they had internally updated the counters of the categories and this allowed to measure reaction time. The next picture was shown $200 \mathrm{~ms}$ after pressing the spacebar. At the end of each block, participants were instructed to report the number of pictures in each category and this was used to measure accuracy. The emotional and non-emotional condition were performed sequentially and the order in which the conditions were completed was counterbalanced across participants. Both conditions consisted of 12 blocks of trials with at random 10 to 14 presented pictures within each block. Each block of trials consisted of shift and repeat trials. A shift trial refers to a trial 
in which the target picture has to be updated on a different category as the preceding picture ( $n$ 1). A repeat trial refers to a trial in which the target stimulus has to be updated on the same category as the preceding picture (n-1). An example of a block of items, including shift and repeat trials, and a stimulus display is shown in Figure 1.

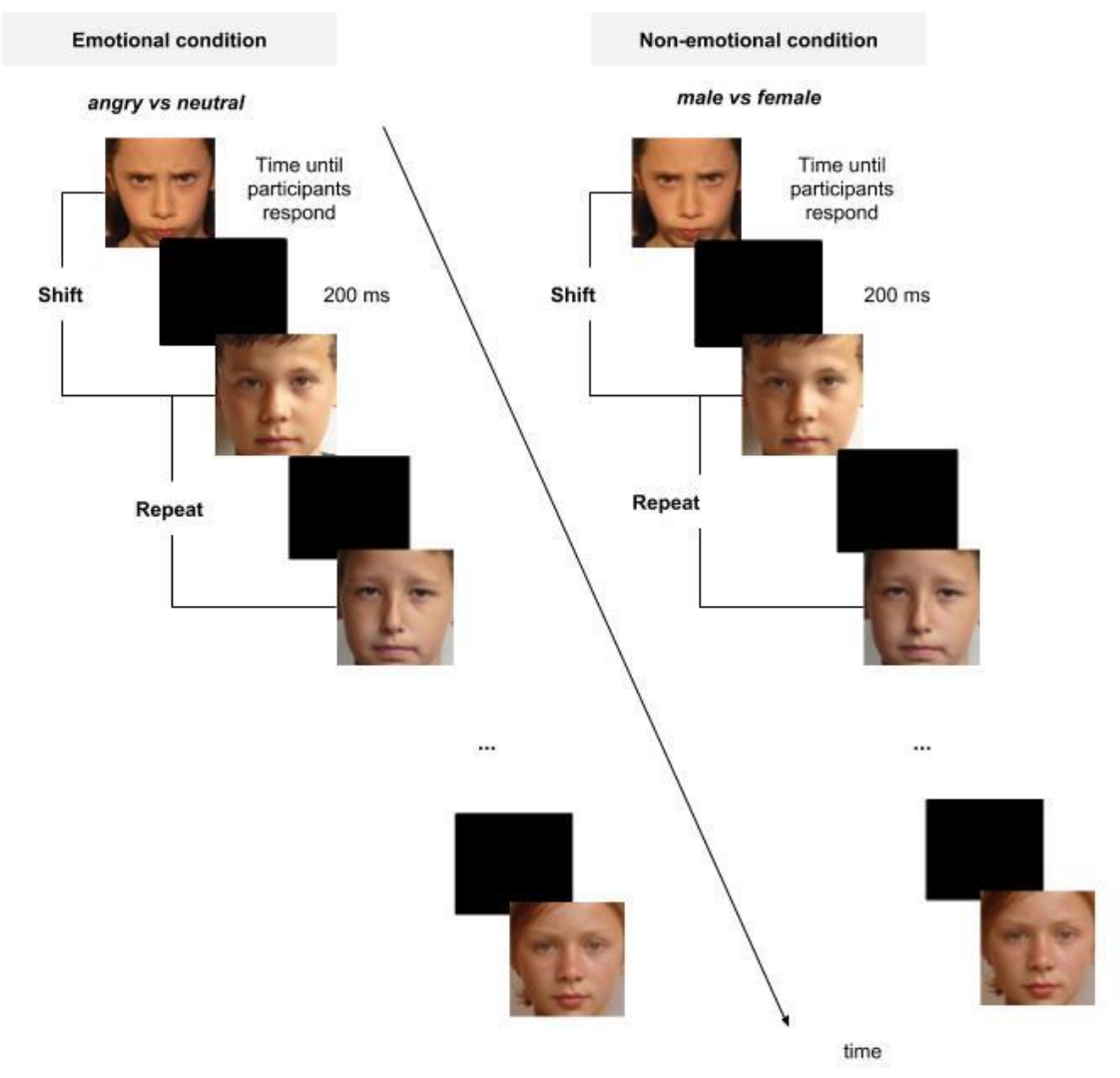

Fig. 1 Example of a block of items and a stimulus display. In the emotional condition (shown in the left half of the figure), participants have to focus on the emotion of the pictures and are asked to perform a mental count of the number of angry and neutral faces. In the non-emotional condition (shown in the right half of the figure), participants have to focus on the gender of the pictures and were asked to keep a silent mental count of the number of male and female faces. In shift trials, the target picture has to be updated on a different category as the preceding 
picture. In repeat trials, the target stimulus has to be updated on the same category as the preceding picture.

\subsection{Procedure}

All participants were invited to the lab at the Faculty of Psychology and Educational Sciences. After signing assent/consent, participants were seated in front of a computer and received task instructions both orally and in writing. Before starting with the experiment proper, participants completed the practice phase including three blocks of items. Next, the adolescents were instructed to complete the experiment phase consisting of 12 blocks of items in both the emotional and the non-emotional condition. After finishing the IST, all participants completed Raven's SPM and filled out the self-report questionnaires. This order of testing prevents priming effects caused by self-report questionnaires and ensures that the intelligence test or questionnaires do not tire or overwhelm participants before starting the IST. One of the parents completed the CBCL while waiting for their child to finish the task.

\subsection{Data Analyses}

In order to analyze shifting impairments in the two groups, a 2 × 2 × 2 (Condition [emotion, gender] x Shift Type [shift, repeat] x Group [dysphoric, non-dysphoric]) repeated-measures (rm)ANCOVA was conducted on response time (RT) data. To further investigate significant interactions, shift costs were calculated by subtracting RTs in repeat trials from RTs on shift trials. Several types of shift costs are examined: (1) to explore general impairments in shifting ability, shift costs across the emotional and the non-emotional condition are examined (general shift cost); (2) to explore shifting impairments related to the task relevance of emotional information, shift costs within the emotional condition [emotion shift cost: RT shift trials (angry-neutral, neutral-angry) minus RT repeat trials (angry-angry, neutral-neutral)] and the non-emotional condition [gender shift cost: RT shift trials (male-female, female-male) minus RT repeat trials (male-male, female-female)] are assessed; and (3) to explore shift and repeat 
trials within the emotional condition, shift and repeat sequences within the emotional condition are compared, referred to as valence face $N-1$ followed by valence face $N$ (angry-neutral, neutral-angry; angry-angry, neutral-neutral). The effort required to engage attention towards angry faces, is calculated by subtracting reaction times in neutral-neutral trials from reaction times in neutral-angry trials (engagement cost). The effort required to disengage attention from angry faces towards neutral faces, is calculated by subtracting reaction times in angry-angry trials from reaction times in angry-neutral trials (disengagement cost).

To ensure that no other relevant variables were related to the differences in shifting ability between the dysphoric and non-dysphoric group, we reran all analyses and added rumination, anxiety symptoms, overall level of psychopathology symptoms (CBCL Total Problems), and intelligence (total score on Raven's SPM) as covariates of no interest. Since all effects remained significant after adding all abovementioned covariates simultaneously to the model, the results of this additional analysis are not further discussed. Effects sizes are provided as eta squared $\left(\eta^{2}\right)$ and Cohen's $d$, as appropriate. Alpha was set at $p=0.05$, two-tailed. Analogous to previous IST studies (e.g., De Lissnyder, Koster, Everaert, et al., 2012; Demeyer et al., 2012), median RT were used in the RT analyses to reduce the influence of outliers on the data. Overall means and SDs as a function of group are shown in Table 2 . The average accuracy rate was $75 \%$, with a significant difference between conditions, $F(1,52)=58.41, p<.001, \eta^{2}=.52$. Consistent with earlier research in adults (Koster et al., 2013), accuracy rates were higher in the emotional condition $(M=86 \%, S D=11 \%)$ compared to the non-emotional condition $(M=64 \%, S D=$ $17 \%$ ). There was no significant difference in accuracy rate between both groups, $F(1,52)=$ $1.42, p=.24, \eta^{2}=.01$. 
Table 2

Mean response times and standard deviations (in $\mathrm{ms}$ ) for the different trial types as a function of group

\begin{tabular}{llllll}
\hline & & \multicolumn{2}{c}{ Dysphoric } & \multicolumn{2}{c}{ Non-dysphoric } \\
\cline { 2 - 6 } & & M & SD & M & SD \\
\hline Emotion condition & & & 2043 & 531 \\
\cline { 2 - 6 } & Switch & 2076 & 550 & 1518 & 541 \\
\cline { 2 - 6 } & No-switch & 1324 & 285 & 1976 & 487 \\
\hline & Angry-neutral & 2059 & 502 & 2185 & 662 \\
\hline \multirow{3}{*}{ Gender condition } & Neutral-angry & 2116 & 649 & 1612 & 644 \\
& Angry-angry & 1300 & 307 & 1432 & 456 \\
\cline { 2 - 6 } & Neutral-neutral & 1416 & 348 & 1939 & 445 \\
\cline { 2 - 6 } & Switch & 1816 & 290 & 1293 & 356 \\
\cline { 2 - 6 } & No-switch & 1318 & 277 & & \\
\hline
\end{tabular}

\section{Results}

\subsection{Group Characteristics}

As expected, groups differed on depressive symptoms, $F(1,52)=81.66, p<.001, \eta^{2}=$ .61 , with a significantly higher score in the dysphoric group compared to the non-dysphoric group. The mean score on rumination did not significantly differ between both groups, $F(1,51)$ $=2.31, p=.135, \eta^{2}=.04$. One-way ANOVAs indicated significant group differences on anxiety symptoms, $F(1,51)=16.92, p<.001, \eta^{2}=.25$, total problem scores, $F(1,47)=4.72$, $p=.035, \eta^{2}=.09$, and age, $F(1,52)=7.17, p=.01, \eta^{2}=.12$. No significant differences between the two groups were found for intelligence $F(1,51)=.67, p=.41, \eta^{2}=.01$, or gender distribution, $\chi^{2}(1,54)=2.06, p=.151($ Table 1$)$.

\subsection{Shifting Impairments in Emotional and Non-emotional Condition}


The results of the rmANCOVA with Condition (emotion, gender) and Shift Type (shift, repeat) as within-subject factors and Group (dysphoric, non-dysphoric) as between-subject factor indicated a significant main effect of Condition, $F(1,49)=5.26, p=.026, \eta^{2}=.05$, with slower response times to the emotion condition $(M=1793 \mathrm{~ms}, S D=488 \mathrm{~ms})$ than to the gender condition $(M=1620 \mathrm{~ms}, S D=340 \mathrm{~ms})$. Analyses also revealed a significant main effect of Shift Type, $F(1,49)=14.22, p<.001, \eta^{2}=.07$, with slower response times to shift trials $(M=$ $1963 \mathrm{~ms}, S D=403 \mathrm{~ms})$ than to repeat trials $(M=1366 \mathrm{~ms}, S D=346 \mathrm{~ms})$. Most importantly, analyses showed a significant three-way interaction among Condition, Shift Type, and Group, $F(1,49)=10.66, p=.002, \eta^{2}=.03^{1}$. To further explore these results, we examined general and condition-specific shift costs. There were no significant differences between the groups with regard to general shift cost, $t(52)=.07, p=.946$, Cohen's $d=.02$. Results of between-group analyses showed that the shift cost in the emotion condition was significantly higher in the dysphoric group compared to the non-dysphoric group, $t(52)=-2.46, p=.017$, Cohen's $d=.65$, while there was a trend significant group difference on shift costs in the gender condition, $t(51)$ $=1.95, p=.056$, Cohen's $d=.50$. Moreover, results of within-group comparisons revealed that, for the dysphoric group, the shift cost in the emotion condition was significantly higher than in the gender condition, $t(19)=2.55, p=.02$, Cohen's $d=.78$. For the non-dysphoric group, however, the shift cost in the gender condition was significantly higher than the shift cost in the emotion condition, $t(33)=-2.13, p=.04$, Cohen's $d=.38$ (Figure 2a).

\subsection{Valence-specific Shifting Impairments}

The results of the rmANCOVA with Valence Face $N-1$ (neutral, angry) and Valence Face $N$ (neutral, angry) as within-subject factors and Group (dysphoric, non-dysphoric) revealed a significant interaction between Valence Face $N$ and Group, $F(1,49)=6.28, p=.016, \eta^{2}=.04$,

\footnotetext{
${ }^{1}$ The three-way interaction is also significant when excluding referred adolescents with low CDI scores from the non-dysphoric group, $F(1,43)=9.88, p=.003, \eta^{2}=.03$.
} 
and between Valence Face $N-1$ and Valence Face $N, F(1,49)=6.89, p=.012, \eta^{2}=.06$. Most importantly, a significant three-way interaction was obtained between Valence Face $N$-1, Valence Face $N$, and Group, $F(1,49)=4.64, p=.036, \eta^{2}=.04^{2}$. Results of between-group analyses showed no significant differences between groups with regard to the engagement cost, $t(52)=.39, p=.70$, Cohen's $d=.11$, while the disengagement cost was significantly higher in the dysphoric group compared to the non-dysphoric group, $t(52)=-3.22, p=.002$, Cohen's $d$ $=.88$. By comparison, results of within-group comparisons revealed that, for the non-dysphoric group, the engagement (neutral to angry) cost was significantly higher than the disengagement cost (angry to neutral), $t(33)=3.47, p=.001$, Cohen's $d=.91$. No significant differences between engagement and disengagement cost emerged in the dysphoric group, $t(19)=-.55, p$ $=.59$, Cohen's $d=.12$ (Figure 2b).
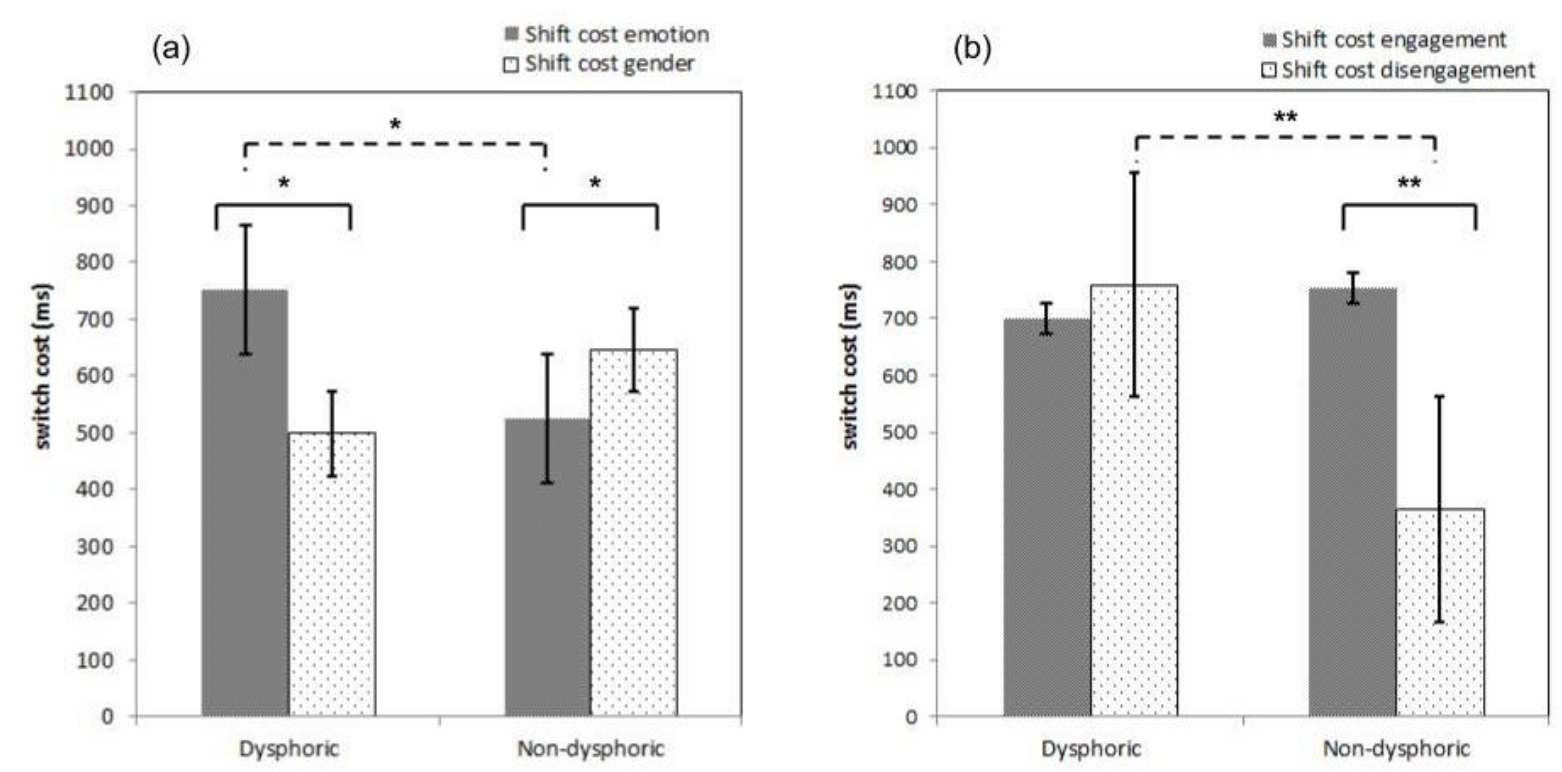

\footnotetext{
${ }^{2}$ The three-way interaction is trend significant when excluding referred adolescents with low CDI scores from the non-dysphoric group, $F(1,43)=3.37, p=.073, \eta^{2}=.03$.
} 
Fig. 2 (a) Mean shift cost (RT shift trials minus $R T$ repeat trials) and standard error of the mean in the emotion versus the gender condition for non-dysphorics and dysphorics. (b) Mean shift cost and standard error of the mean in the engagement (RT neutral-angry trials minus RT neutral-neutral trials) versus the disengagement (RT angry-neutral trials minus RT angry-angry trials) condition for non-dysphorics and dysphorics. Note. ${ }^{*} p<.05 ; * * p \leq .01$; *** $p<.001$.

\section{Discussion}

The main goal of this study was to assess internal shifting impairments related to emotional and non-emotional information in dysphoric adolescents by adopting the IST (De Lissnyder, Koster, \& De Raedt, 2012). Pertinent to the study hypotheses we found that: (1) dysphoric adolescents did not show general shifting impairments relative to unaffected adolescents; (2) the dysphoric group did experience specific shifting difficulties in the emotional condition of the task compared to the non-dysphoric group; and (3) while there were no significant group differences when shifting from neutral to negative information (i.e. engagement), dysphoric adolescents showed greater impairments when shifting from negative to neutral information (i.e. disengagement) compared to non-dysphoric adolescents.

In general, the results provide evidence for emotion-specific shifting impairments in dysphoric adolescents. Specifically, dysphoric adolescents only showed greater shifting impairments compared to non-dysphoric adolescents when emotional features of the presented pictures had to be processed, but not when non-emotional features were task-relevant. This corresponds to the results of previous cognitive control studies in dysphoric or depressed adolescents (e.g., Kyte et al., 2005; Ladouceur et al., 2006; Wante et al., 2015) and is in line with the idea that cognitive control processes are particularly hampered when processing emotional information (Joormann, Yoon, et al., 2007). The current results are also consistent with a study of Lo and Allen (2011) indicating an affective bias in internal shifting in depressed 
youth and multiple internal shifting studies among adults at risk for developing depression (De Lissnyder, Koster, Goubert, et al., 2012; Demeyer et al., 2012; Koster et al., 2013). The results further showed that non-dysphoric adolescents showed a trend significantly higher shift cost in the non-emotional condition (i.e. male vs. female faces) compared to dysphoric adolescents. This indicates that non-dysphoric adolescents do not perform better, and even perform slightly worse, in the non-emotional condition compared to dysphoric adolescents. This result clearly points to the absence of shifting impairments in response to non-emotional information in dysphoric adolescents and is consistent with a number of previous studies that failed to find general cognitive control deficits in depressed and dysphoric adolescents (Vilgis et al., 2015).

Noteworthy, however, the present findings contrast with earlier research using the IST in clinically depressed adults which provided evidence for general but no emotion-specific shifting impairments (De Lissnyder, Koster, Everaert, et al., 2012). Importantly, our study included dysphoric adolescents, while adult studies often include depressed participants with a history of chronicity or multiple depressive episodes. Thus, a potential explanation for the discrepancy is that general cognitive control impairments are a feature of severe and chronic depression, while dysfunctional cognitive processing of emotional stimuli is already observed in mildly depressed individuals at risk for the development of more severe depressive episodes (Joormann \& Gotlib, 2007). This idea is also supported by a study of Holler et al. (2014), which indicated lowered general set shifting in severely, but not in mildly, depressed adolescents.

Within-group analyses further revealed that while dysphoric adolescents showed a higher shift cost in the emotional condition (i.e., angry vs. neutral faces) compared to the nonemotional condition (i.e., male vs. female faces), the non-dysphoric group experienced a lower shift cost in the emotional condition versus the non-emotional condition. The latter finding, which points to a faster shifting response when processing emotional features in healthy adolescents, corresponds to the results of a prior IST study in adults (De Lissnyder, Koster, \& 
De Raedt, 2012) and can be explained by the fact that the ability to quickly categorize and to flexibly shift attention towards and away from emotional expressions is important for adaptive social functioning and may have evolutionary significance by facilitating a prompt response to emotionally salient and threatening stimuli (De Lissnyder, Koster, \& De Raedt, 2012; Lang, Bradley, \& Cuthbert, 1990). This generally faster response to distinguish and shift between emotional information compared to neutral information was not observed in the dysphoric group and in fact, the opposite tendency was found. This clearly indicates that emotional processing is perturbed in dysphoric adolescents.

Further analyses of valence-specific effects in the emotional condition revealed no significant differences between both groups with regard to engagement or shifting from neutral to angry faces. Importantly, however, a higher disengagement cost was found in the dysphoric group relative to unaffected adolescents. In other words, dysphoric adolescents experienced greater difficulties in shifting away from angry faces compared to non-dysphoric adolescents. These results correspond to earlier studies in adults (e.g., Koster et al., 2011; Levens \& Gotlib, 2010) and provide evidence for impaired attentional disengagement from negative faces in dysphoric adolescents. This finding also suggests that the dysphoric group experienced specific difficulties to direct attention away from emotional information (top-down, higher-order cognitive processing), instead of having an early attentional bias towards emotional information (i.e. early automatic processing). By contrast, unaffected adolescents not only disengaged quicker from negative faces relative to dysphoric youths but also relative to their own engagement toward angry faces. Such an effect can be explained by the fact that disengaging from a negative stimulus is a natural emotion regulating response to change the emotional impact (Ochsner \& Gross, 2005) and can thus be considered as a more automatic and adaptive process than engaging attention toward negative stimuli in healthy adolescents. The lack of such a differential effect in dysphoric youth could explain their tendency to negatively elaborate 
on negative information and their inability to redirect attention to neutral or more positive information (Jones, Siegle, \& Thase, 2008) .

These results of the present investigation may have important clinical implications since the inability to shift or to disengage attention from negative information may intensify negative emotional responses and hinder the use of adaptive ER strategies, such as cognitive reappraisal or positive refocusing (Joormann \& D'Avanzato, 2010; Kovacs, Joormann, \& Gotlib, 2008). In this context, targeting internal cognitive control over emotional stimuli may be a promising avenue for future depression prevention programs. Specifically, the ability to disengage attention from negative information during stressful events will also make it more easy to cognitively reappraise the situation and thereby decrease negative affect (Troy \& Mauss, 2011). On this topic, research in depressed adults has already provided promising evidence for a significant effect of cognitive control training on ER and stress reactivity (Hoorelbeke, Koster, Vanderhasselt, Callewaert, \& Demeyer, 2015).

The present study has several strengths. First, in contrast to the majority of previous cognitive control studies in depressed or dysphoric adolescents (Vilgis et al., 2015), our study included emotional stimuli, which enabled us to investigate both general and emotion-specific shifting impairments. Moreover, the IST adopted in this study included pictures of faces instead of verbal stimuli order to provide higher ecological validity (Bradley et al., 1997). Second, while the focus of previous work has mainly been on the cognitive control in relation to externally presented stimuli, the IST paradigm allows us to investigate internal cognitive control by assessing the ability to shift attention between mental presentations held in working memory. This may be a particularly relevant process to investigate in dysphoric individuals given the negative internal or self-focused attention that characterizes depression (Pyszczynski \& Greenberg, 1987). Finally, studying underlying mechanisms in dysphoric youngsters is important, in part, because adolescence proves a critical period of vulnerability to depression 
and because of the elevated risk of a depressive disorder in adulthood following first-onset depression in adolescence (Fombonne, Wostear, Cooper, Harrington, \& Rutter, 2001). Moreover, while previous studies in depressed adults are limited by depression severity, recurrent episodes, and often prior pharmacological interventions, studying dysphoric adolescents enables us to have a clearer look at the baseline cognitive processes.

However, in interpreting the results of this study, several limitations should be acknowledged. First, we assessed depressive symptoms through a self-report questionnaire. Although the CDI is a reliable screening instrument (Kovacs, 1992), the use of a structured clinical interview is required to check the presence of a depressive disorder (Hien et al., 1998). Second, in contrast to multiple studies investigating the processing of sad information in depression or dysphoria (e.g., Hankin et al., 2010; Joormann, Talbot, \& Gotlib, 2007; Kyte et al., 2005), the current study examined shifting impairments in relation to angry faces. Since sad faces were not included in our stimulus set, it was not possible to compare the effects of different types of negative stimuli or to determine whether the observed effects are stimulusspecific or relate to negative emotional stimuli in general. Third, a large number of participants were excluded due to accuracy rates near chance level (i.e., < 60\%). Notably, the accuracy rates obtained in the present study, especially in the gender condition, are clearly lower compared to multiple previous studies in which an IST including adult faces was employed in adults and average accuracy rates ranged between 83 and $88 \%$ (e.g., De Lissnyder, Koster, \& De Raedt, 2012; De Lissnyder, Koster, Everaert, et al., 2012; Demeyer et al., 2012). This incongruence may be explained by the different age groups studied (Zelazo \& Carlson, 2012). Specifically, previous studies using an IST with emotional faces were conducted in adult samples (e.g., De Lissnyder, Koster, \& De Raedt, 2012; De Lissnyder, Koster, Everaert, et al., 2012; Demeyer et al., 2012), while the current study tested internal shifting in a sample of young adolescents with a mean age of 12 years old. Interestingly, however, the accuracy rates in the current study are 
comparable with the studies of Lo and Allen (2011) and Beckwe, Deroost, Koster, De Lissnyder, and De Raedt (2014) in which an IST with verbal stimuli was used in youth and young adults. Therefore, an alternative explanation for the relatively low accuracy rates in the current study may be found in the type of stimuli included in the IST. In contrast to the firstmentioned studies using pictures of adult faces as target stimuli (e.g., De Lissnyder, Koster, \& De Raedt, 2012; De Lissnyder, Koster, Everaert, et al., 2012; Demeyer et al., 2012), the present study used child faces and the study of Lo and Allen (2011) and Beckwe et al. (2014) used verbal stimuli, which may both be more ambiguous compared to adult faces (Bradley et al., 1997; Wild et al., 2000). In line with this argument, a face recognition study of Wild et al. (2000) showed that both children and adults performed significantly less accurate in classifying children's faces by gender compared to classifying adult faces. Based on these considerations, it can be concluded that future studies using the IST in children or adolescents are warranted to replicate the current findings. Moreover, these studies should consider the use of other stimuli (e.g., adult faces) or should provide more time for practice with feedback to explore whether these adjustments improve accuracy rates on the IST in general and in the non-emotional condition in particular.

Finally, it will be interesting to replicate this study on adolescents who are vulnerable to depression and previously depressed adolescents to explore if cognitive control plays a role in the development or recurrence of depression and not merely represents a symptom of depressed mood. In fact, if future longitudinal research continues to demonstrate the underlying role of maladaptive cognitive control processes, directly targeting these processes with computerized training tasks may improve the efficacy of standard prevention programs (Siegle, Ghinassi, \& Thase, 2007). 


\section{Conclusions}

In sum, dysphoric adolescents experienced specific shifting impairments when emotional features of the pictures had to be processed. Moreover, valence-specific analyses revealed greater difficulties shifting from angry to neutral faces relative to non-dysphoric adolescents, while there were no significant group differences when shifting from neutral to negative information. It will be important for future studies to investigate the association between internal shifting and adaptive ER. Moreover, longitudinal studies are needed to investigate shifting impairments in at risk-youngsters and adolescents previously diagnosed with depression to explore the role of internal cognitive control processes in the development and maintenance of depression. 


\section{References}

AACAP. (2007). Practice Parameters for the assessment and treatment of children and adolescents with depressive disorders. Journal of the American Academy of Child and Adolescent Psychiatry, 46(11), 1503-1526.

Achenbach, T. M., \& Rescorla, L. (2001). Manual for the ASEBA school-age forms \& profiles: An intergrated system of mult-informant assessment. Brulington, VT: University of Vermont, Research Center for Children, Youth, \& Families.

Bakker, F. C., Wieringen, P. C. W. v., Ploeg, H. M. v. d., \& Spielberger, C. D. (2004). Beoordelings-Vragenlijst voor kinderen. ZBV-K. Een Nederlandstalige bewerking van de State-Trait Anxiety Inventory for Children (STAIC) van Spielberger e.a. . Amsterdam: Harcourt Assessment B.V.

Balazs, J. (2013). Adolescent Subthreshold Depression and Anxiety. European Psychiatry, 28.

Beck, A. T. (1976). Cognitive therapy and the emotional disorders. New York: Meridian.

Beckwe, M., Deroost, N., Koster, E. H. W., De Lissnyder, E., \& De Raedt, R. (2014). Worrying and rumination are both associated with reduced cognitive control. Psychological Research-Psychologische Forschung, 78(5), 651-660. doi: 10.1007/s00426-013-05175

Benedek, M., Jauk, E., Sommer, M., Arendasy, M., \& Neubauer, A. C. (2014). Intelligence, creativity, and cognitive control: The common and differential involvement of executive functions in intelligence and creativity. Intelligence, 46, 73-83. doi: 10.1016/j.intell.2014.05.007

Birmaher, B., Ryan, N. D., Williamson, D. E., Brent, D. A., Kaufman, J., Dahl, R. E., .. . Nelson, B. (1996). Childhood and adolescent depression: A review of the past 10 years .1. Journal of the American Academy of Child and Adolescent Psychiatry, 35(11), $1427-$ 1439. doi: 10.1097/00004583-199611000-00011 
Bloch, Y., Aviram, S., Faibel, N., Govezensky, J., Braw, Y., Rabany, L., \& Walter, G. (2013). The Correlation Between Impaired Attention and Emotional Reactivity in Depressed Adolescent Patients. Journal of Neuropsychiatry and Clinical Neurosciences, 25(3), 233-236.

Bradley, B. P., Mogg, K., Millar, N., BonhamCarter, C., Fergusson, E., Jenkins, J., \& Parr, M. (1997). Attentional biases for emotional faces. Cognition \& Emotion, 11(1), 25-42.

Brydges, C. R., Anderson, M., Reid, C. L., \& Fox, A. M. (2013). Maturation of Cognitive Control: Delineating Response Inhibition and Interference Suppression. Plos One, 8(7). doi: 10.1371/journal.pone.0069826

Carroll, J. B. (1993). The Wechsler Intelligence Scale for Children, 3rd Edition (Wisc-Iii) Wechsler,D. Journal of Psychoeducational Assessment, 134-143.

Chambers, R., Lo, B. C. Y., \& Allen, N. B. (2008). The impact of intensive mindfulness training on attentional control, cognitive style, and affect. Cognitive Therapy and Research, 32(3), 303-322. doi: DOI 10.1007/s10608-007-9119-0

Chun, M. M., Golomb, J. D., \& Turk-Browne, N. B. (2011). A Taxonomy of External and Internal Attention. Annual Review of Psychology, Vol 62, 62, 73-101. doi: DOI 10.1146/annurev.psych.093008.100427

Clark, D. A., \& Beck, A. T. (2010). Cognitive theory and therapy of anxiety and depression: convergence with neurobiological findings. Trends in Cognitive Sciences, 14(9), 418424. doi: 10.1016/j.tics.2010.06.007

Coyne, J. C. (1976). Depression and Response of Others. Journal of Abnormal Psychology, 85(2), 186-193. doi: Doi 10.1037//0021-843x.85.2.186

Cracco, E., Van Durme, K., \& Braet, C. (2015). Validation of the FEEL-KJ: An Instrument to Measure Emotion Regulation Strategies in Children and Adolescents. Plos One, 10(9). doi: 10.1371/journal.pone.0137080 
Craighead, W. E., Smucker, M. R., Craighead, L. W., \& Ilardi, S. S. (1998). Factor analysis of the Children's Depression Inventory in a community sample. Psychological Assessment, 10(2), 156-165. doi: Doi 10.1037/1040-3590.10.2.156

De Lissnyder, E., Koster, E. H. W., \& De Raedt, R. (2012). Emotional Interference in Working Memory is Related to Rumination. Cognitive Therapy and Research, 36(4), 348-357. doi: 10.1007/s10608-011-9352-4

De Lissnyder, E., Koster, E. H. W., Derakshan, N., \& De Raedt, R. (2010). The association between depressive symptoms and executive control impairments in response to emotional and non-emotional information. Cognition \& Emotion, 24(2), 264-280. doi: $10.1080 / 02699930903378354$

De Lissnyder, E., Koster, E. H. W., Everaert, J., Schacht, R., Van den Abeele, D., \& De Raedt, R. (2012). Internal cognitive control in clinical depression: General but no emotionspecific impairments. Psychiatry Research, 199(2), 124-130. doi: 10.1016/j.psychres.2012.04.019

De Lissnyder, E., Koster, E. H. W., Goubert, L., Onraedt, T., Vanderhasselt, M. A., \& De Raedt, R. (2012). Cognitive control moderates the association between stress and rumination. Journal of Behavior Therapy and Experimental Psychiatry, 43(1), 519-525. doi: 10.1016/j.jbtep.2011.07.004

Demeyer, I., De Lissnyder, E., Koster, E. H. W., \& De Raedt, R. (2012). Rumination mediates the relationship between impaired cognitive control for emotional information and depressive symptoms: A prospective study in remitted depressed adults. Behaviour Research and Therapy, 50(5), 292-297. doi: 10.1016/j.brat.2012.02.012

Diamond, A. (2002). Normal development of prefrontal cortex from birth to young adulthood: Cognitive functions, anatomy, and biochemistry. . In D. T. Stuss \& R. T. Knight (Eds.), Principles of frontal lobe function (pp. 466-503). New York: Oxford University Press. 
Favre, T., Hughes, C., Emslie, G., Stavinoha, P., Kennard, B., \& Carmody, T. (2009). Executive Functioning in Children and Adolescents with Major Depressive Disorder. Child Neuropsychology, 15(1), 85-98. doi: 10.1080/09297040802577311

Flanagan, D. P., \& McGrew, K. S. (1998). Interpreting intelligence tests from contemporary Gf-Gc theory: Joint confirmatory factor analysis of the WJ-R and KAIT in a non-white sample. Journal of School Psychology, 36(2), 151-182. doi: 10.1016/S00224405(98)00003-X

Fombonne, E., Wostear, G., Cooper, V., Harrington, R., \& Rutter, M. (2001). The Maudsley long-term follow-up of child and adolescent depression 2. Suicidality, criminality and social dysfunction in adulthood. British Journal of Psychiatry, 179, 218-223. doi: 10.1192/bjp.179.3.218

Garavan, H. (1998). Serial attention within working memory. Memory \& Cognition, 26(2), 263276. doi: 10.3758/Bf03201138

Gehring, W. J., Bryck, R. L., Jonides, J., Albin, R. L., \& Badre, D. (2003). The mind's eye, looking inward? In search of executive control in internal attention shifting. Psychophysiology, 40(4), 572-585. doi: 10.1111/1469-8986.00059

Gibb, B. E., Benas, J. S., Grassia, M., \& McGeary, J. (2009). Children's Attentional Biases and 5-HTTLPR Genotype: Potential Mechanisms Linking Mother and Child Depression. Journal of Clinical Child and Adolescent Psychology, 38(3), 415-426. doi: $10.1080 / 15374410902851705$

Gilboa-Schechtman, E., Ben-Artzi, E., Jeczemien, P., Marom, S., \& Hermesh, H. (2004). Depression impairs the ability to ignore the emotional aspects of facial expressions: Evidence from the Garner task. Cognition \& Emotion, 18(2), 209-231. doi: $10.1080 / 02699930341000176$ 
Gotlib, I. H., Krasnoperova, E., Yue, D. N., \& Joormann, J. (2004). Attentional biases for negative interpersonal stimuli in clinical depression. Journal of Abnormal Psychology, 113(1), 127-135. doi: 10.1037/0021-843x.113.1.127

Grant, D. A., \& Berg, E. A. (1948). A behavioral analysis of degree of reinforcement and ease of shifting to new responses in a Weigl-type card-sorting problem. J Exp Psychol, 38(4), 404-411.

Grob, A., \& Smolenski, C. (2005). Fragebogen zur Erhebung der Emotionsregulation bei Kindern und Jugendlichen (FEEL-KJ) Bern: Huber Verlag.

Gunther, T., Konrad, K., De Brito, S. A., Herpertz-Dahlmann, B., \& Vloet, T. D. (2011). Attentional functions in children and adolescents with ADHD, depressive disorders, and the comorbid condition. Journal of Child Psychology and Psychiatry, 52(3), 324-331. doi: 10.1111/j.1469-7610.2010.02320.x

Hames, J. L., Hagan, R. H., \& Joine, T. E. (2013). Interpersonal Processes in Depression. Annual Review of Clinical Psychology, 9, 355-377.

Han, G., Klimes-Dougan, B., Jepsen, S., Ballard, K., Nelson, M., Houri, A., . . . Cullen, K. (2012). Selective neurocognitive impairments in adolescents with major depressive disorder. Journal of Adolescence, 35(1), 11-20. doi: 10.1016/j.adolescence.2011.06.009

Hankin, B. L., Gibb, B. E., Abela, J. R. Z., \& Flory, K. (2010). Selective Attention to Affective Stimuli and Clinical Depression Among Youths: Role of Anxiety and Specificity of Emotion. Journal of Abnormal Psychology, 119(3), 491-501. doi: 10.1037/A0019609

Hardin, M. G., Schroth, E., Pine, D. S., \& Ernst, M. (2007). Incentive-related modulation of cognitive control in healthy, anxious, and depressed adolescents: development and psychopathology related differences. Journal of Child Psychology and Psychiatry, 48(5), 446-454. doi: 10.1111/j.1469-7610.2006.01722.x 
Hien, D., Matzner, F., First, M., Spitzer, R., Williams, J., \& Gibbon, M. (1998). Structured clinical interview for DSM-IV childhood diagnoses (KID-SCID). New York: Biometrics research presentation.

Holler, K., Kavanaugh, B., \& Cook, N. E. (2014). Executive Functioning in Adolescent Depressive Disorders. Journal of Child and Family Studies, 23(8), 1315-1324. doi: $10.1007 / \mathrm{s} 10826-013-9789-\mathrm{z}$

Hoorelbeke, K., Koster, E. H. W., Vanderhasselt, M. A., Callewaert, S., \& Demeyer, I. (2015). The influence of cognitive control training on stress reactivity and rumination in response to a lab stressor and naturalistic stress. Behaviour Research and Therapy, 69, 1-10. doi: 10.1016/j.brat.2015.03.010

Horowitz, J. L., \& Garber, J. (2006). The prevention of depressive symptoms in children and adolescents: A meta-analytic review. Journal of Consulting and Clinical Psychology, 74(3), 401-415. doi: 10.1037/0022-006X.74.3.401

Joiner, T. E., Alfano, M. S., \& Metalsky, G. I. (1992). When Depression Breeds Contempt Reassurance Seeking, Self-Esteem, and Rejection of Depressed College-Students by Their Roommates. Journal of Abnormal Psychology, 101(1), 165-173. doi: Doi $10.1037 / 0021-843 x .101 .1 .165$

Jones, N. P., Siegle, G. J., \& Thase, M. E. (2008). Effects of rumination and initial severity on remission to Cognitive Therapy for depression. Cognitive Therapy and Research, 32(4), 591-604. doi: 10.1007/s10608-008-9191-0

Joormann, J., \& D'Avanzato, C. (2010). Emotion regulation in depression: Examining the role of cognitive processes. Cognition \& Emotion, 24(6), 913-939. doi: $10.1080 / 02699931003784939$ 
Joormann, J., \& Gotlib, I. H. (2007). Selective attention to emotional faces following recovery from depression. Journal of Abnormal Psychology, 116(1), 80-85. doi: Doi $10.1037 / 0021-843 x .116 .1 .80$

Joormann, J., Talbot, L., \& Gotlib, I. H. (2007). Biased processing of emotional information in girls at risk for depression. Journal of Abnormal Psychology, 116(1), 135-143. doi: Doi $10.1037 / 0021-843 x .116 .1 .135$

Joormann, J., Yoon, K. L., \& Zetsche, U. (2007). Cognitive inhibition in depression. Applied \& Preventive Psychology, 12(3), 128-139. doi: DOI 10.1016/j.appsy.2007.09.002

Kaslow, N. J., Rehm, L. P., \& Siegel, A. W. (1984). Social-Cognitive and Cognitive Correlates of Depression in Children. Journal of Abnormal Child Psychology, 12(4), 605-620. doi: Doi 10.1007/Bf00916853

Koch, K., Pauly, K., Kellermann, T., Seiferth, N. Y., Reske, M., Backes, V., . . . Habel, U. (2007). Gender differences in the cognitive control of emotion: An fMRI study. Neuropsychologia, 45(12), 2744-2754. doi: 10.1016/j.neuropsychologia.2007.04.012

Koster, E. H. W., De Lissnyder, E., \& De Raedt, R. (2013). Rumination is characterized by valence-specific impairments in switching of attention. Acta Psychologica, 144(3), 563570. doi: 10.1016/j.actpsy.2013.09.008

Koster, E. H. W., De Lissnyder, E., Derakshan, N., \& De Raedt, R. (2011). Understanding depressive rumination from a cognitive science perspective: The impaired disengagement hypothesis. Clinical Psychology Review, 31(1), 138-145. doi: 10.1016/j.cpr.2010.08.005

Kovacs, M. (1992). Children's Depression Inventory (CDI) manual. New York: Multi-Health Systems. 
Kovacs, M., Joormann, J., \& Gotlib, I. H. (2008). Emotion (Dys)regulation and Links to Depressive Disorders. Child Development Perspectives, 2(3), 149-155. doi: DOI $10.1111 / \mathrm{j} .1750-8606.2008 .00057 . x$

Kyte, Z. A., Goodyer, I. M., \& Sahakian, B. J. (2005). Selected executive skills in adolescents with recent first episode major depression. Journal of Child Psychology and Psychiatry, 46(9), 995-1005. doi: 10.1111/j.1469-7610.2004.00400.x

Ladouceur, C. D., Dahl, R. E., Williamson, D. E., Birmaher, B., Axelson, D. A., Ryan, N. D., \& Casey, B. J. (2006). Processing emotional facial expressions influences performance on a Go/NoGo task in pediatric anxiety and depression. Journal of Child Psychology and Psychiatry, 47(11), 1107-1115. doi: 10.1111/j.1469-7610.2006.01640.x

Ladouceur, C. D., Dahl, R. E., Williamson, D. E., Birmaher, B., Ryan, N. D., \& Casey, B. J. (2005). Altered emotional processing in pediatric anxiety, depression, and comorbid anxiety-depression. Journal of Abnormal Child Psychology, 33(2), 165-177. doi: $10.1007 / \mathrm{s} 10802-005-1825-\mathrm{z}$

Langner, O., Dotsch, R., Bijlstra, G., Wigboldus, D. H. J., Hawk, S. T., \& van Knippenberg, A. (2010). Presentation and validation of the Radboud Faces Database. Cognition \& Emotion, 24(8), 1377-1388. doi: 10.1080/02699930903485076

Levens, S. M., \& Gotlib, I. H. (2010). Updating Positive and Negative Stimuli in Working Memory in Depression. Journal of Experimental Psychology-General, 139(4), 654-664. doi: $10.1037 / \mathrm{a} 0020283$

Lewinsohn, P. M., Rohde, P., Seeley, J. R., Klein, D. N., \& Gotlib, L. H. (2000). Natural course of adolescent major depressive disorder in a community sample: Predictors of recurrence in young adults. American Journal of Psychiatry, 157(10), 1584-1591. doi: DOI 10.1176/appi.ajp.157.10.1584 
Li, C. S. R., Zhang, S., Duann, J. R., Yan, P. S., Sinha, R., \& Mazure, C. M. (2009). Gender Differences in Cognitive Control: an Extended Investigation of the Stop Signal Task. Brain Imaging and Behavior, 3(3), 262-276. doi: 10.1007/s11682-009-9068-1

Lo, B. C. Y., \& Allen, N. B. (2011). Affective bias in internal attention shifting among depressed youth. Psychiatry Research, 187(1-2), 125-129. doi: 10.1016/j.psychres.2010.10.001

Maalouf, F. T., Clark, L., Tavitian, L., Sahakian, B. J., Brent, D., \& Phillips, M. L. (2012). Bias to negative emotions: A depression state-dependent marker in adolescent major depressive disorder. Psychiatry Research, 198(1), 28-33. doi: 10.1016/j.psychres.2012.01.030

Mattison, R. E., Handford, H. A., Kales, H. C., \& Goodman, A. L. (1990). Four-Year Predictive Value of the Children's Depression Inventory Psychological Assessment, 2(2), 169-174.

Miyake, A., Friedman, N. P., Emerson, M. J., Witzki, A. H., Howerter, A., \& Wager, T. D. (2000). The unity and diversity of executive functions and their contributions to complex "frontal lobe" tasks: A latent variable analysis. Cognitive Psychology, 41(1), 49-100. doi: 10.1006/cogp.1999.0734

Mueller, S. C. (2011). The influence of emotion on cognitive control: relevance for development and adolescent psychopathology. Frontiers in Psychology, 2. doi: 10.3389/Fpsyg.2011.00327

Mueller, S. C., De Rubeis, J., Lange, D., Pawelzik, M. R., \& Sutterlin, S. (2016). Sensitivity to Social Exclusion in Major Depressive Disorder Predicts Therapeutic Outcome after Inpatient Treatment. Psychotherapy and Psychosomatics, 85(1), 50-52. doi: $10.1159 / 000437147$ 
Neshat-Doost, H. T., Taghavi, M. R., Moradi, A. R., Yule, W., \& Dalgleish, T. (1998). Memory for emotional trait adjectives in clinically depressed youth. Journal of Abnormal Psychology, 107(4), 642-650.

Ochsner, K. N., \& Gross, J. J. (2005). The cognitive control of emotion. Trends in Cognitive Sciences, 9(5), 242-249. doi: 10.1016/j.tics.2005.03.010

Pine, D. S., Cohen, E., Cohen, P., \& Brook, J. (1999). Adolescent depressive symptoms as predictors of adult depression: Moodiness or mood disorder? American Journal of Psychiatry, 156(1), 133-135.

Pyszczynski, T., \& Greenberg, J. (1987). Self-Regulatory Perseveration and the Depressive Self-Focusing Style - a Self-Awareness Theory of Reactive Depression. Psychological Bulletin, 102(1), 122-138. doi: Doi 10.1037//0033-2909.102.1.122

Ridderinkhof, K. R., Ullsperger, M., Crone, E. A., \& Nieuwenhuiss, S. (2004). The role of the medial frontal cortex in cognitive control. Science, 306(5695), 443-447. doi: DOI 10.1126/science. 1100301

Rushton, J. P. (1998). The g factor: The science of mental ability. Politics and the Life Sciences, $17(2), 230-232$.

Shemesh, E., Yehuda, R., Rockmore, L., Shneider, B. L., Emre, S., Bartell, A. S., . . Newcorn, J. H. (2005). Assessment of depression in medically ill children presenting to pediatric specialty clinics. Journal of the American Academy of Child and Adolescent Psychiatry, 44(12), 1249-1257. doi: 10.1097/01.chi.0000181043.29208.a2

Siegle, G. J., Ghinassi, F., \& Thase, M. E. (2007). Neurobehavioral therapies in the 21st century: Summary of an emerging field and an extended example of cognitive control training for depression. Cognitive Therapy and Research, 31(2), 235-262. doi: DOI $10.1007 / \mathrm{s} 10608-006-9118-6$ 
Spielberger, C. D. (1973). Manual for the state-trait anxiety inventory. Palo Alto, CA: Consulting Psychologists Press.

Tavitian, L. R., Ladouceur, C. D., Nahas, Z., Khater, B., Brent, D. A., \& Maalouf, F. T. (2014). Neutral face distractors differentiate performance between depressed and healthy adolescents during an emotional working memory task. European Child \& Adolescent Psychiatry, 23(8), 659-667. doi: 10.1007/s00787-013-0492-9

Timbremont, B., \& Braet, C. (2002). Children's Depression Inventory, Nederlandstalige versie (Children's Depression Inventory, Dutch version). Lisse: Swets \& Zeitlinger.

Timbremont, B., Braet, C., Bosmans, G., \& Van Vlierberghe, L. (2008). Cognitive Biases in Depressed and Non-Depressed Referred Youth. Clinical Psychology \& Psychotherapy, 15(5), 329-339. doi: 10.1002/Cpp.579

Troy, A. S., \& Mauss, I. B. (2011). Resilience in the face of stress: emotion regulation as a protective factor. In S. M. Southwick, B. T. Litu, D. Charney, \& M. J. Friedman (Eds.), Resilience and Mental Health: Challenges Across the Lifespan (pp. 30-44). New York: Cambridge University Press.

Verfaillie, E., Theuwis, L., \& Wante, L. (2012). Gevalideerde fotodatabase van gelaatsuitdrukkingen bij kinderen en jongeren tussen 8 en 14 jaar. Universiteit Gent.

Verhulst, F. C., Ende, J. v. d., \& Koot, H. M. (1996). Handleiding voor de CBCL/4-18. Rotterdam: Sophia Kinderziekenhuis, Erasmus MC.

Vilgis, V., Silk, T. J., \& Vance, A. (2015). Executive function and attention in children and adolescents with depressive disorders: a systematic review. European Child \& Adolescent Psychiatry, 24(4), 365-384. doi: 10.1007/s00787-015-0675-7

Wager, T. D., Jonides, J., \& Smith, E. E. (2006). Individual differences in multiple types of shifting attention. Memory \& Cognition, 34(8), 1730-1743. doi: Doi 10.3758/Bf03195934 
Wante, L., Mueller, S. C., Demeyer, I., De Raedt, R., \& Braet, C. (2015). The Role of Interference and Inhibition Processes in Dysphoric Early Adolescents. Journal of Clinical Child and Adolescent Psychology. doi: 10.1080/15374416.2015.1102068

Wild, H. A., Barrett, S. E., Spence, M. J., O'Toole, A. J., Cheng, Y. D., \& Brooke, J. (2000). Recognition and sex categorization of adults' and children's faces: Examining performance in the absence of sex-stereotyped cues. Journal of Experimental Child Psychology, 77(4), 269-291. doi: 10.1006/jecp.1999.2554

Wilkinson, P. O., \& Goodyer, I. M. (2006). Attention difficulties and mood-related ruminative response style in adolescents with unipolar depression. Journal of Child Psychology and Psychiatry, 47(12), 1284-1291. doi: 10.1111/j.1469-7610.2006.01660.x

Worchel, F. F., Hughes, J. N., Hall, B. M., Stanton, S. B., Stanton, H., \& Little, V. Z. (1990). Evaluation of Subclinical Depression in Children Using Self-Report, Peer-Report, and Teacher-Report Measures. Journal of Abnormal Child Psychology, 18(3), 271-282. doi: Doi 10.1007/Bf00916565

Zelazo, P. D., \& Carlson, S. M. (2012). Hot and Cool Executive Function in Childhood and Adolescence: Development and Plasticity. Child Development Perspectives, 6(4), 354360. doi: 10.1111/j.1750-8606.2012.00246.x 